\title{
A novel Mcm1-dependent element in the SWI4, CLN3, CDC6, and CDC47 promoters activates $M / G_{1}$-specific transcription
}

\author{
Christopher J. McInerny, ${ }^{1}$ Janet F. Partridge, ${ }^{1,2}$ Glen E. Mikesell, ${ }^{1}$ Davis P. Creemer, ${ }^{1}$ and \\ Linda L. Breeden ${ }^{1,3}$ \\ ${ }^{1}$ Fred Hutchinson Cancer Research Center, Basic Sciences Division, Seattle, Washington 98104 USA
}

We have identified a novel promoter element that confers $M / G_{\mathbf{1}}$-specific transcription in Saccharomyces cerevisiae. This element, which we call an ECB (early cell cycle box), was first identified in the SWI4 promoter, but it is also present in the promoter of a $G_{1}$ cyclin $C \bar{L} N 3$, as well as in the promoters of three DNA replication genes: $C D C 6, C D C 47$, and $C D C 46$. Transcripts from all five of these genes oscillate during the cell cycle and peak at the $M / G_{1}$ boundary, as do isolated ECB elements in reporter constructs. The ECB element contains an $\mathrm{Mcm} 1$ binding site to which $\mathrm{Mcm} 1$ binds in vitro, and an Mcm1-VP16 fusion, which places a constitutive activator on Mcm1-binding sites in vivo, can deregulate ECB-containing promoters. $\mathbf{M c m} 1$ is a transcription factor that is also required for minichromosome maintenance. We provide evidence that the replication defect of $\mathrm{mcm} 1$ mutants can be suppressed by ectopic $C D C 6$ transcription. Periodic expression of SWI4 and CLN3 may be important for cell cycle progression, as we find that these genes are both haploinsufficient and rate limiting for $G_{1}$ progression. We suggest that ECB-regulated gene products play critical roles in promoting the initiation of S-phase, both by regulating CLN1 and CLN2 transcription and as components of the initiation complex on origins of replication.

[Key Words: ECB; SWI4; CLN3; CDC6; CDC47; cell cycle; transcription]

Received February 6, 1997; revised version accepted April 8, 1997.

Nearly 100 genes have been identified in Saccharomyces cerevisiae that are transcribed at specific stages of the cell cycle. Only a minority of these gene products have been shown to play critical roles in cell cycle progression; they have been identified as unstable proteins that are rate limiting for specific processes in the cell cycle. These gene products are transcribed when they are required, and high-level constitutive expression of them is often deleterious to the cell. Understanding how these proteins function and how their expression is regulated is key to understanding the control of the cell cycle.

Swi4 is a transcription factor critical for the $G_{1}$-to-S transition, which associates with Swi6 to form the complex that activates transcription of $H O$ and the $G_{1} / S$ specific cyclins $C L N 1$ and $C L N 2$ (for review, see Breeden 1996). SWI4 transcription is periodic, and it peaks just before the peak of transcription of its target genes (Breeden and Mikesell 1991, 1994). Stabilization or constitutive transcription of SWI4 increases the level of

\footnotetext{
${ }^{2}$ Present address: MRC Human Genetics Unit, Western General Hospital, Edinburgh, Scotland EH4 2XU.

${ }^{3}$ Corresponding author.

E-MAIL lbreeden@fred.fhcrc.org; FAX (206) 667-6526.
}

CLN1 and CLN2 transcription throughout the cell cycle (Breeden and Mikesell 1994) and leads to the aberrant budding morphology that is typical of cells overproducing CLN1 and CLN2 (Breeden and Mikesell 1991; Lew and Reed 1993).

$C D C 6, C D C 46$, and $C D C 47$ are all transcribed at about the same time as SWI4 (Bueno and Russell 1992; Zwerschke et al. 1994; Dalton and Whitbread 1995). These proteins are required for the initiation of DNA synthesis (for review, see Stillman 1996), and defects in these genes cause a high rate of minichromosome loss that can be suppressed by increasing the number of replication origins on the DNA (Brewer and Fangman 1987; Hogan and Koshland 1992). The periodic transcription of CDC6 is clearly important because high-level constitutive expression of Cdc6 (Bueno and Russell 1992; Piatti et al. 1995), or its Schizosaccharomyces pombe homolog Cdc18 (Kelly et al. 1993), delays M phase and loss of function of these proteins prevents DNA synthesis but allows a lethal $M$ phase to proceed on schedule.

Certainly the best known of the stage-specific regulators are the cyclins. In the budding yeast, nine cyclins have been identified that bind and activate the Cdc28 kinase (Cross 1995). This single cyclin-dependent kinase 
(CDK) exerts primary control over the major transitions in the cell cycle, so the successive expression of different classes of cyclins must provide the specificity for these transitions. Cln3 stands out among the cyclins because even small changes in its expression have the effect of either speeding or delaying the transition from $G_{1}$ to $S$ phase (Nash et al. 1988; Cross 1988, 1989). The only known activity of the $\mathrm{Cln} 3$ kinase is in activating the burst of $G_{1} / S$-specific cyclin transcription that is mediated by the Swi4/Swi6 and Mbpl/Swi6 transcription complexes (Dirick et al. 1995; Stuart and Wittenberg 1996), but neither the kinase substrate nor its mechanism of activation in late G1 has been identified.

In this paper we described a new cell cycle-regulated promoter element that is present in the promoters of a group of genes: SWI4, CLN3, CDC6, CDC47, and $C D C 46$, which are coordinately regulated at the $M / G_{1}$ boundary. This early cell cycle box (ECB) element contains an Mcml-binding site, and we show that $\mathrm{Mcm} 1$ controls ECB gene expression. We provide evidence suggesting the importance of this transcriptional regulation in timing the entry into $S$ phase and in DNA replication.

\section{Results}

Early timing of SWI4 transcription is conferred by a novel cell cycle regulatory element

The SWI4 promoter contains three MCB $(M 7 u I$ cell cycle box) elements that are known to confer $G_{1} / \bar{S}$-specific transcription to many genes. However, deletion of these three known cell cycle regulatory elements does not eliminate the periodicity or the early timing of transcription (Foster et al. 1993). To identify the novel promoter element that is responsible for this early peak of SWI4 transcription, we first showed that the 90-bp region $3^{\prime}$ to the MCB elements (SWI4 $90 \mathrm{bp}$ ) was sufficient to confer this regulation (Fig. 1, top). We then used mutagenic PCR to identify the sequences responsible for the transcriptional activity of the 90-bp fragment. The mutations that reduced transcription were clustered within an 8-bp inverted repeat (Fig.1, bottom), and disruption of these palindromic sequences, or the spacing between them, causes up to a 50-fold drop in transcript levels. The center of the palindrome is a consensus binding sequence for the transcription factor $\mathrm{Mcm} 1$, which acts as an activator and a repressor in different promoter contexts (Jarvis et al. 1989; Passmore et al. 1989; Ammerer 1990; Elble and Tye 1991). To determine whether the specific residues crucial for $\mathrm{Mcml}$ binding are required for the upstream activation sequence (or UAS) activity of this 90-bp fragment, we made a GG $\rightarrow$ CC mutation within the $\mathrm{Mcm} 1$ consensus binding sequence. This change causes a 14-fold drop in transcription compared to wild-type DNA. The minimal Mcml-binding site has been defined by site selection in vitro to require only the 8 bp indicated by the hatched bar in Figure 1 (Wynne and Treisman 1992). This sequence is clearly important, but we also see 5- and 10-fold reductions in UAS activity when single-base substitutions are made in the bases im-
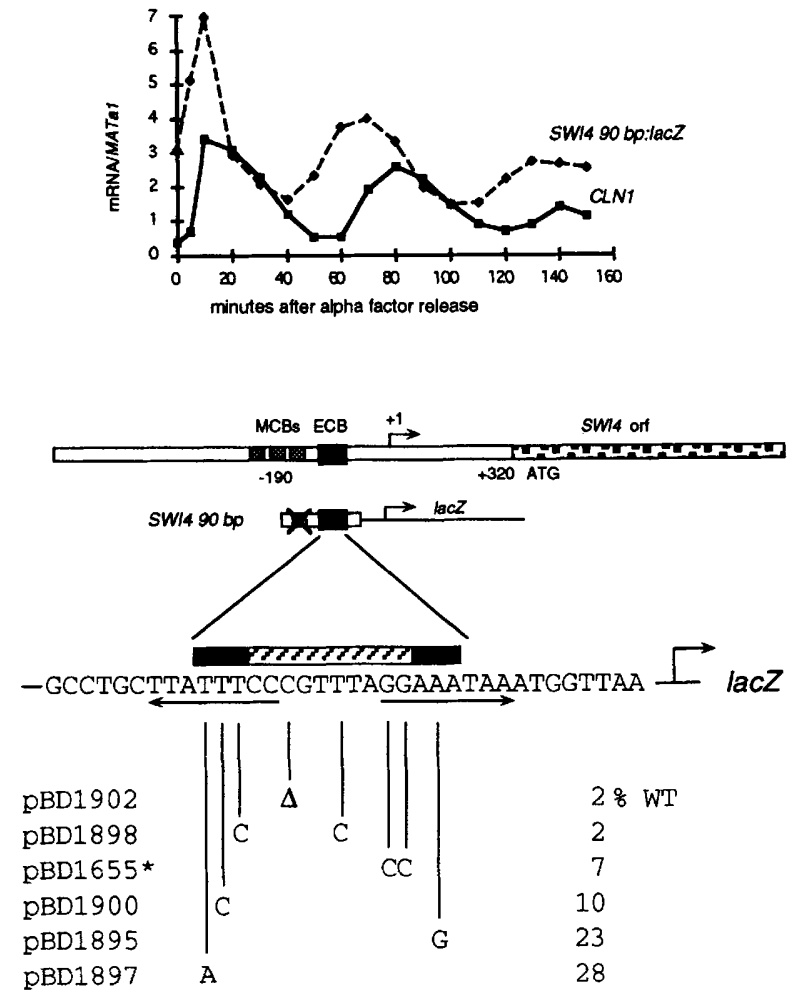

Figure 1. Localizing the novel cell cycle regulatory element in the SWI4 promoter. The central diagram depicts the SWI4 promoter (Foster et al. 1993) in relation to the ATG (+1). Below is shown the relative position of the 90 -bp promoter fragment (SWI4 $90 \mathrm{bp}$ ), which harbors one inactivated MCB as well as novel sequences sufficient to confer early cell cycle regulation to the lacZ transcript (referred to as ECB). The plot shows the oscillation of the SWI4 90 bp-driven lacZ transcript compared to that of $C L N 1$. For this plot, the $1 a c Z$ and $C L N 1$ transcripts were measured through three synchronous cell cycles by $\mathrm{S} 1$ protection. They were quantitated by Phosphorlmaging, normalized to the constitutive MATal mRNA, and plotted as a function of time after release from the $G_{1}$ arrest induced by $\alpha$-factor. The bottom diagram shows six PCR-generated mutants and one site-directed mutant (denoted by the asterisk); the level of transcript from each is listed to the right. The transcriptional activity of each mutant is an average value obtained from three independent transformants. These values were normalized to MATa1 transcript levels and are presented as the percentage obtained from their wild-type counterparts (pBD1478 for the PCR-generated mutants and pBD1577 for the site-directed mutant). The hatched bar above the sequence identifies the minimal Mcml-binding site identified by site selection in vitro (Wynne and Treisman 1992), and the black bars flanking it show the additional sequences required for full UAS activity based on this mutagenesis. pBD1900 has an additional $A \rightarrow G$ change $33 \mathrm{bp} 3^{\prime}$ to the ECB element in a region that is unlikely to contribute to its phenotype.

mediately flanking the minimal Mcml-binding site. This emphasizes the importance of these adjacent sequences for transcription activation.

To assess the potential regulatory role of this UAS element within the SWI4 promoter, we introduced point 
mutations within this sequence and recombined them into the genomic SWI4 promoter. Although SWI4 is an essential gene in the W303 strain background, loss of the element is not a lethal mutation, because transcription persists in this strain. However, loss of only this novel UAS element causes a measurable delay in SWI4 transcription during the cell cycle (Fig. 2) and a concomitant delay in CLN1 and CLN2 transcription (data not shown). The transcript generated from this promoter mutant is still periodic, but it peaks at least 5 min later than wildtype SWI4. The cell cycle regulation that persists is almost certainly conferred by the MCB elements because these elements are known to activate cell cycle-regulated transcription, which peaks in late $\mathrm{G}_{1}$ /Gordon and Campbell 1991; McIntosh et al. 1991). The delay of transcription observed with the mutant UAS indicates that this sequence is required for the early wave of SWI4 transcription. Thus, we will refer to it as an ECB element. It is interesting to note that loss of the ECB element also causes the start site for SWI4 transcription to change (Fig. 2). Thus, both the timing of transcription and the start site selection seem to be governed by the ECB element in exponentially growing cells.

Cell size control and the length of the $G_{1}$ interval are also affected by point mutations in the SWI4 ECB. This phenotype is easily detected in poor carbon sources such as glycerol (Fig. 3) and raffinose (data not shown), where the cell cycle is slow and wild-type cells maintain a very small cell size. Under these conditions, swi4ecb cells have about a $30 \%$ larger volume than their wild-type

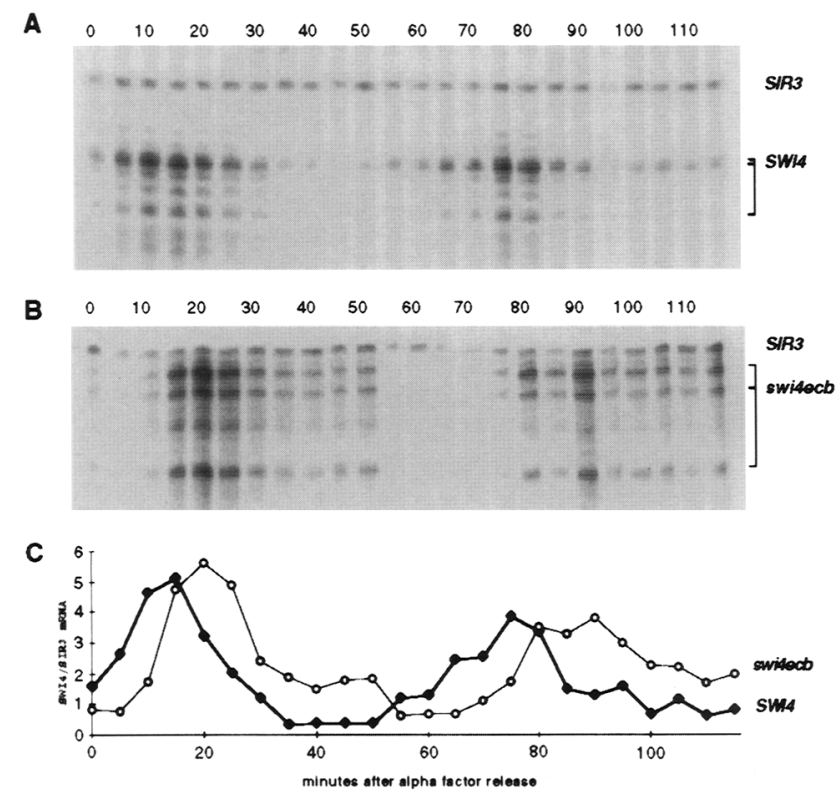

Figure 2. Loss of the ECB element of SWI4 causes a delay of $S W I 4$ transcription and a change in the transcription start site. Wild-type $(A)$ and swi4ecb mutant (B) strains (BY2195) were released from $\alpha$-factor arrest as in Fig. 1, and SWI4 and SIR3 mRNA levels were measured by $\mathrm{S} 1$ protection analysis. SWI4 transcripts, normalized to the invariant SIR3, are plotted in $C$.

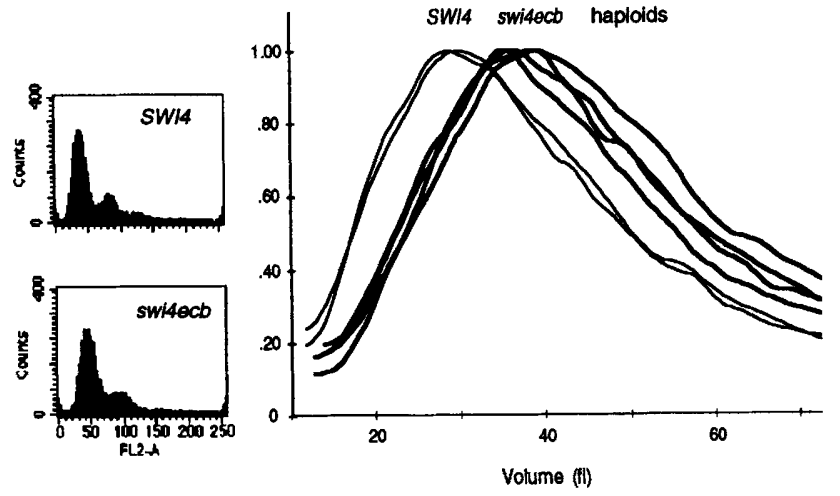

Figure 3. swi4ecb mutants spend more time in $\mathrm{G}_{1}$ and are larger than wild-type cells. Profiles of DNA content and Coulter channelizer measurements of cell volume were carried out for the isogenic SWI4 and swi4ecb mutant strains, growing exponentially in glycerol. The volume measurements are shown in femtoliters $\left(10^{-15}\right.$ liters $)$ on the $x$-axis, and the $y$-axis reflects the frequency with which cells of a given volume were present in the population.

counterparts, and they spend a larger proportion of their time in $G_{1}$ than wild-type cells do. The simplest interpretation of this result is that SWI4 is rate limiting for $\mathrm{G}_{1}$ progression and that ECB-dependent transcription is an important component of its regulation under these conditions. However, we do not see this dramatic shift in size in exponentially growing cells using glucose as a carbon source. This is probably attributable to the additional layers of regulation exerted on CLN1 and CLN2 that are glucose mediated (Tokiwa et al. 1994; Baroni et al. 1994; Barral et al. 1995).

\section{The CDC6, CDC47, and CLN3 promoters also contain functional ECB elements}

To identify other genes that might be coordinately regulated with SWI4, we searched the yeast database with the ECB sequence identified by our mutagenesis and found two closely spaced matches within the CLN3, $C D C 6$, and $C D C 47$ promoters and one in the CDC46 promoter. Interestingly, the transcripts of all four of these genes are periodic and their levels peak at about the same time as SWI4 (Bueno and Russell 1992; Zwerschke et al. 1994; Dalton and Whitbread 1995; see Fig. 6, below), although in the case of $C L N 3$ the significance of this expression pattern has not been investigated (Wittenberg et al. 1990; Fernandez-Sarabia et al. 1992; Tyers et al. 1993; Oehlen and Cross 1994). Figure 4 shows the position and sequence of these putative ECB elements relative to the other known promoter elements. To determine whether the ECB sites within the CDC6 promoter confer cell cycle-regulated transcription, a 54-bp fragment containing these sites was cloned into a UASdeficient lacZ reporter plasmid. As with the SWI4 90-bp fragment, the $C D C 6$ 54-bp promoter fragment confers periodic transcription to lac $Z$. Moreover, this transcrip- 


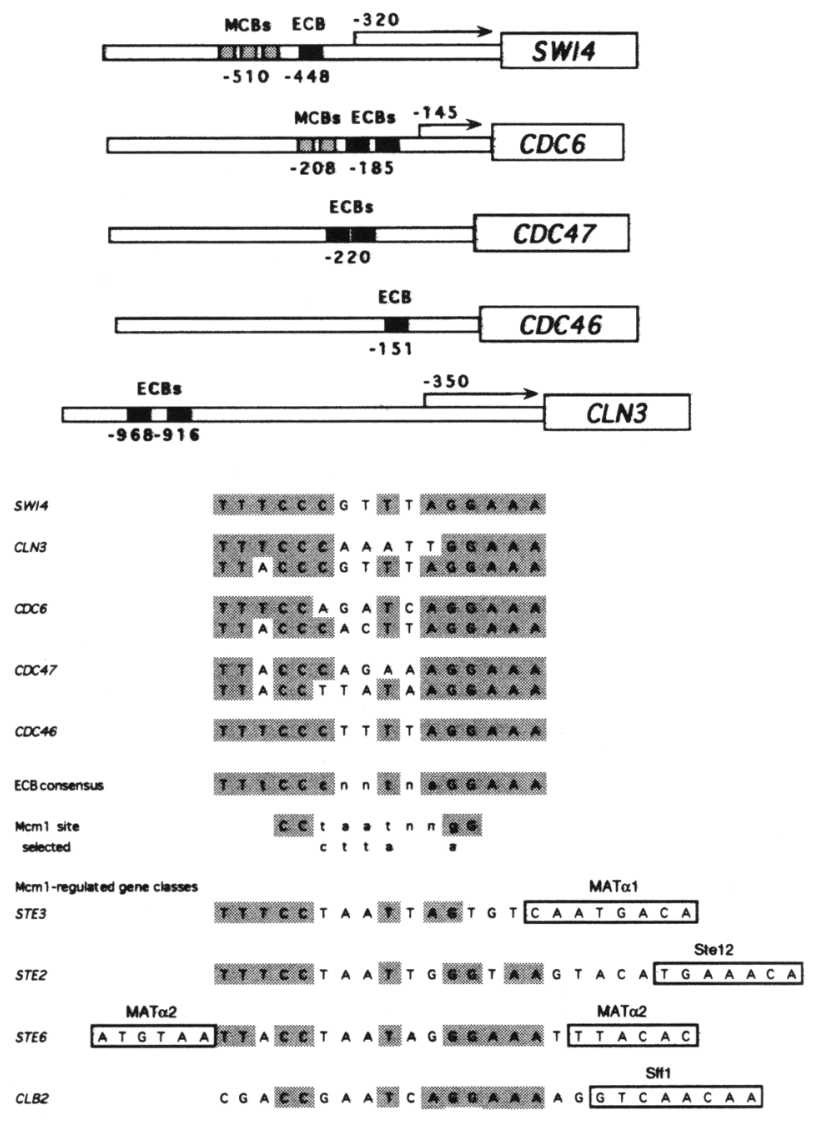

Figure 4. Strong homology to the SWI4 ECB element was found in the promoters of four other periodically expressed genes. The position of these potential ECBs are indicated by black boxes. The other known cell cycle regulatory elements (MCBs) are also depicted relative to the ATG $(+1)$ as indicated . The untranslated leaders, where known, are unusually long (indicated with arrows). In the case of $C L N 3$, the leader is $\sim 350 \mathrm{bp}$ long and contains an ATG (J.F. Partridge and L.L. Breeden, unpubl., M. Polymenis and E.V. Schmidt, in prep.). The sequences conserved within the putative ECBs are highlighted below and compared to the minimal binding site consensus determined for Mcm1 by site selection (Wynne and Treisman 1992). Also, representative binding sites for $\mathrm{Mcml}$ from the other known classes of Mcm1-regulated genes are listed. STE3 is one of the genes that is induced in $\alpha$ cells by Mcml/Mat $\alpha 1$ complexes. STE2 is induced by $\alpha$-factor and activated by $\mathrm{Mcml} / \mathrm{Ste} 12$. STE6 is one of the a-specific genes that is repressed in $\alpha$ cells by $\mathrm{Mcm} 1 / \mathrm{Mat} \alpha 2$, and $C L B 2$ is one of the $\mathrm{G}_{2}$-specific genes activated as a result of $\mathrm{Mcm} 1 / \mathrm{Sff} 1$ action (Herskowitz et al. 1992; Sprague and Thorner 1992; Johnson 1995).

tion precedes that of $C L N 1$ by $\sim 10$ min and parallels the profile of the genomic CDC6 transcript (Fig. 5A,B).

The two putative ECB elements in the CDC47 promoter are immediately adjacent to one another, so we tested a 38-bp fragment containing these two contiguous elements for cell cycle-regulated UAS activity. The CDC47 ECB fragment also confers periodic transcription, and the timing of peak transcription is equivalent to that of SWI4 and CDC6 (Fig. 5C). Because this CDC47 fragment includes only ECB sequences flanked by three additional base pairs at each end, we conclude that the ECB elements are sufficient to induce a wave of transcription that immediately precedes CLN1 and CLN2 transcription.

The database search for ECB elements also revealed two consensus ECBs within the CLN3 promoter. Kuo and Grayhack (1994) had shown previously that there are three binding sites for $\mathrm{Mcm} 1$ in the CLN3 promoter. Two of these fit the ECB element consensus, and they are positioned $\sim 600$-bp $5^{\prime}$ from the start site for transcription (Fig. 4). These ECB elements are also active, as judged by the fact that the CLN3 promoter containing the putative ECB elements confers cell cycle regulated transcription in CLN3 ECB:lacZ, but mutation of these putative ECBs and the third Mcm1-binding site results in constitutive transcription at or below the trough levels observed with the wild-type promoter fragment (Fig 5D). In addition, transcription from the CLN3 ECB reporter (CLN3 129:1acZ) is also cell cycle regulated (Fig. 6A).

Oscillations of the endogenous CLN3 transcript have been observed previously using both induced and elutriated synchronies in several different laboratories (Wittenberg et al. 1990; Fernandez-Sarabia et al. 1992; Tyers et al. 1993; Oehlen and Cross 1994). To confirm and extend these earlier studies, we have quantitated the oscillation of CLN3 transcription using two different synchrony protocols (Fig. 6) and have observed a reproducible threefold fluctuation in $C L N 3$ transcript levels. This wave of transcription occurs after the burst of $G_{2}$ cyclin transcription, before that of CLN1 and CLN2 transcription (Fig. 6A,B), and at a similar cell cycle time to $C D C 6$ and SWI4 (Fig. 6C,D).

\section{CLN3 transcription peaks at the $M / G_{1}$ boundary}

To define the phase of the cell cycle during which ECB activation is maximal, we monitored the major events in the cell cycle in parallel with transcript measurements. Transcript levels for CLN3, CLN1, and CLB2 after $\alpha$ factor release are plotted in Figure 7A. Parallel samples were scored for budding and for the presence of metaphase and anaphase spindles (Fig. 7B), and FACS analysis was carried out to follow the DNA synthesis cycle (Fig. 7C). The CLN1 mRNA level peaks at 20 and $90 \mathrm{~min}$, when the majority of cells are unbudded and lack spindles. It is especially clear in the first cycle that the CLN1 peak occurs during $\mathrm{G}_{1}$, before significant amounts of DNA have been synthesized. The CLB2 mRNA level peaks after $S$ phase is complete (50 $\mathrm{min}$ ), when the majority of cells contain spindles, and it drops at the end of $M$ phase. The peak levels of $C L N 3$ mRNA occur $70 \mathrm{~min}$ after release from the arrest, and CDC6 and SWI4 mRNAs also peak at this time (data not shown). At the 70 min time point, $80 \%$ of the cells contain either metaphase or anaphase spindles (Fig. 7B), and most of the cells have had a $\mathrm{G}_{2}$ DNA content for at least $20 \mathrm{~min}$ (Fig. $7 \mathrm{C}$ ). An increase in the population of cells with $G_{1}$ DNA content is also evident at this time. Thus, SWI4, CDC6, 
A

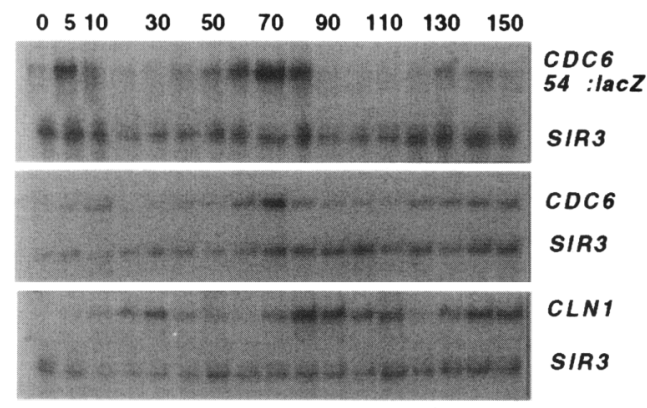

B

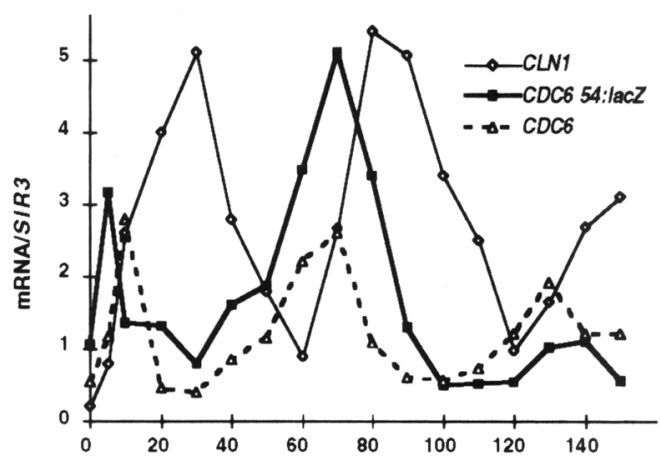

C
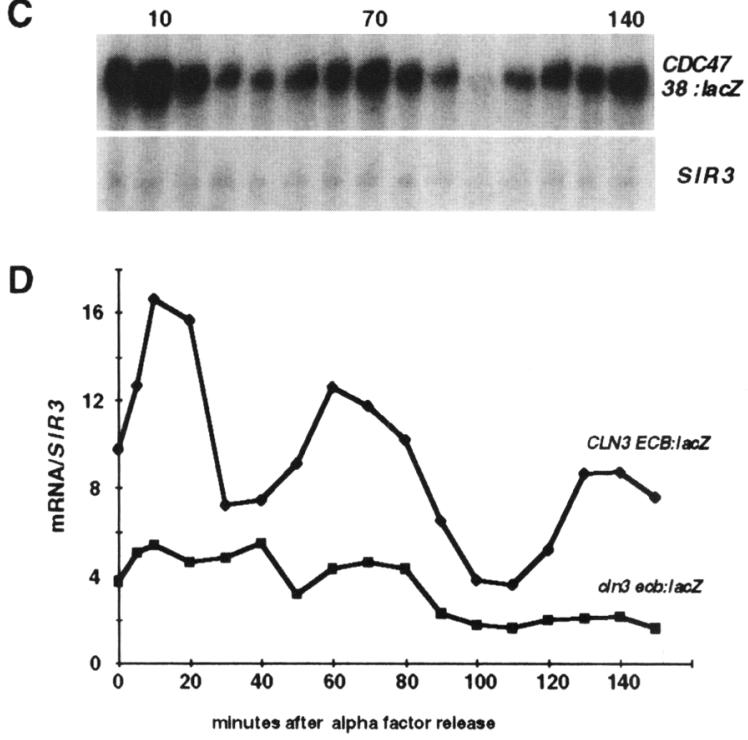

Figure 5. The ECB-containing promoter fragments from CDC6, CDC47, and CLN3 are sufficient to confer cell cycle regulation that peaks $10 \mathrm{~min}$ before $C L N 1$ transcript peaks. $\{A \mid$ The CDC6 ECB reporter transcript (CDC6 54:1acZ) compared to genomic $C D C 6$ and $C L N 1$ transcripts in an $\alpha$-factor synchrony experiment carried out as in Figure 1 and plotted in $B$. (C) Transcripts from the $C D C 47 \mathrm{ECB}$ reporter (CDC47 38:1acZ) were monitored through three cell cycles after release from $\alpha$-factor arrest. SIR3 serves as the internal control. (D) Transcripts from the wild-type $C L N 3$ promoter $(-678$ to -123 ) or the equivalent ECB-deficient promoter $c \ln 3 \mathrm{ecb}$, driving $l a c Z$ transcription, were quantitated over three cell cycles by $\mathrm{S} 1$ protection as above.

and $C L N 3$ mRNA levels peak late in M phase and/or in very early $G_{1}$.

\section{ECB activation is $M c m 1$ dependent}

To determine whether $\mathrm{Mcml}$ can bind to the ECB element within the SWI4 promoter, gel retardation assays were performed with the 90-bp ECB region from SWI4. Figure 8A shows that one prominent bandshift complex can be observed when wild-type cell extracts are incubated with the SWI4 ECB fragment (lane 2). This complex can be competed away by addition of excess cold $C L N 3, C D C 6$, or $C D C 47$ ECB fragments (lanes 6-11), but it is not affected by $e c b$ mutant derivatives of the SWI4 or CDC47 fragments (lanes 5,12). The swi4ecb mutant fragment was amplified from the swi 4 ecb mutant strain (see Fig. 2), and the $c d c 47 e c b$ mutant, which substitutes AAA for TTT in both ECBs in the 38:IacZ reporter construct (Fig. $5 \mathrm{C}$ ), is completely inactive in vivo (data not shown). Neither of these ECB mutants (lanes 5,12 ) can compete for this binding, even at 100 -fold molar excess. Thus, both complex formation in vitro and the ability to activate transcription in vivo requires the ECB sequence. Furthermore, this bandshift complex can be quantitatively supershifted upon addition of antibodies specific to $\mathrm{Mcm} 1$ (lane 13). This indicates that $\mathrm{Mcml}$ is present in all of the detectable ECB-binding complexes.

To address the role of $\mathrm{Mcm} 1$ in SWI5 and CLB2 transcription in vivo, Althoefer et al. (1995) constructed a GAL1-regulated Mcm1-VP16 fusion protein that possesses the DNA-binding specificity of $\mathrm{Mcm} 1$ but should activate transcription constitutively through the VP16 domain. With this construct they were able to induce ectopic transcription of SWI5 and CLB2 at cell cycle stages when they are not normally transcribed. This indicates that $\mathrm{Mcm} 1 \mathrm{can}$ bind and activate transcription of these promoters. However, this GAL1:MCM1-VP16 fusion is overexpressed and lethal to the cells. To examine the effect of an Mcml-VP16 fusion on ECB-containing promoters through the cell cycle when it was expressed from its native promoter, we constructed such a fusion and integrated it into the genome of a $c d c 15-1 \mathrm{mcm} 1$ deletion strain. This fusion protein complements the $m c m 1$ deletion and supports nearly normal growth rates (data not shown). We synchronized these cells by releasing them from a $c d c 15-1$ arrest and found that SWI4, $C D C 6$, and $C L N 3$ transcripts are present continuously throughout the cell cycle in the Mcm1-VP16 strain (Fig. $8 \mathrm{~B})$. This is not attributable to lack of synchrony because histone H2B transcription cycles normally. Rather, it appears that the cells are synchronized and that $\mathrm{Mcm} 1-$ VP16 is activating these three genes throughout the cell cycle. SWI4 and CDC6 also have MCB elements in their promoters that are known to promote $\mathrm{G}_{1} / \mathrm{S}$-specific transcription (Gordon and Campbell 1991; McIntosh et al. 1991). The fact that we see continuous expression of SWI4 and CDC6 in mcm1-VP16 cells indicates that the presence of the Mcm1-VP16 fusion protein interferes with activation via the MCB elements. This is consistent with our results with the swi4ecb strain and suggests again that the ECB is the primary regulator in rapidly growing cells. 

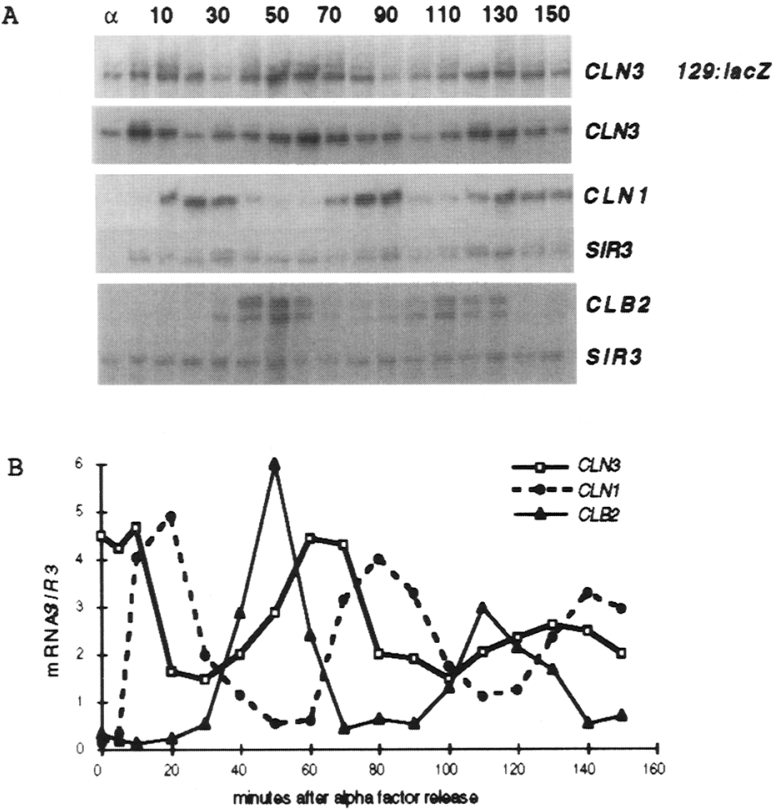

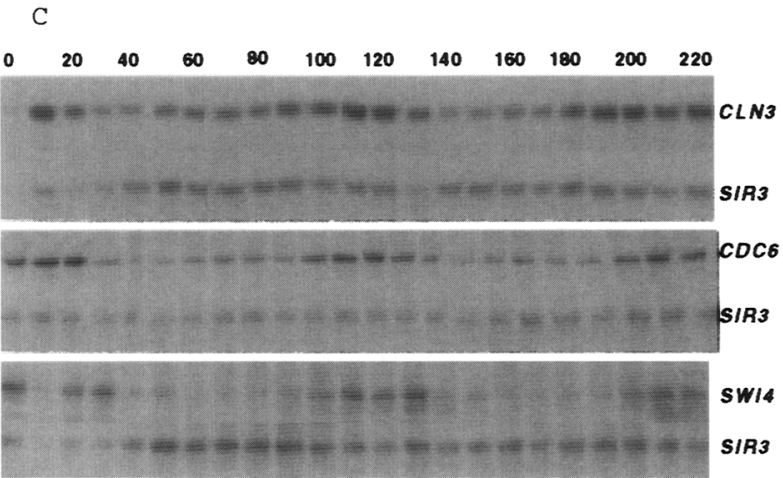

D

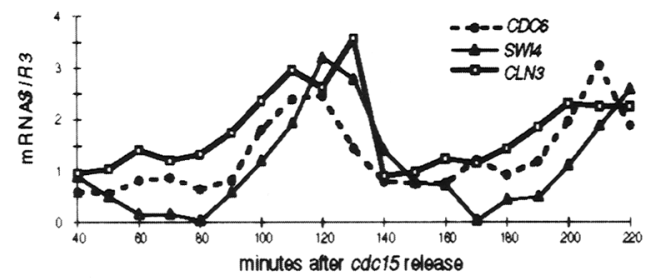

Figure 6. $C L N 3$ message shows periodic accumulation through three consecutive cell cycles and peaks after CLB2 and before $C L N 1$. (A) Wild-type cells were released from $\alpha$-factor arrest, and the CLN3,CLN1,CLB2, and SIR3 mRNA levels were measured and quantitated as before. The CLN3 ECB reporter (CLN3 129:lacZ) was also monitored in these cells. SIR3 serves as the internal control and the cyclin transcripts, normalized to SIR3, are plotted in B. $|C|$ Temperature-sensitive cdc15-2 cells (MATa tyrl leu2 ura3 his 7 gal1 can1 cdc15-2 from L. Hartwell, Fred Hutchinson Cancer Research Center/ were grown at $25^{\circ} \mathrm{C}$ in YEP glucose and arrested in late mitosis by shifting to $37^{\circ} \mathrm{C}$ for $180 \mathrm{~min}$. Cells were released synchronously from the arrest by rapid cooling to $25^{\circ} \mathrm{C}$, and $C L N 3, C D C 6$, SWI4, and SIR3 mRNA levels were monitored as in Fig. 1 and are plotted in $D$.

Combined, these in vivo and in vitro experiments support the view that $\mathrm{Mcml}$ is a critical component of the ECB-binding complex in the SWI4, CDC6, and CLN3 promoters. The Mcm1-VP16 fusion shows that a modification of $\mathrm{Mcml}$ can disrupt ECB-regulated gene expression, and the gel retardation experiments demonstrate that $\mathrm{Mcm} 1$ can bind ECB elements directly.

The minichromosome maintenance defect of $\mathrm{mcm} 1$ strains is suppressed by constitutive CDC6 expression

$\mathrm{Mcml}, \mathrm{Cdc6}$, Cdc46, and Cdc47 are all required for minichromosome maintenance (Maine et al. 1984; Hogan and Koshland 1992), and we have shown that $C D C 6, C D C 46$, and $C D C 47$ promoters all contain Mcm 1-dependent ECB elements. To determine whether the role of $\mathrm{Mcml}$ in transcription of $C D C 6$ could be the cause of its minichromosome maintenance defect, we expressed $C D C 6$ from the GAL1 promoter on a plasmid (pGAL:CDC6) in an $m c m 1-1$ strain. These cells were grown in raffinose, so that the GAL:CDC6 gene would be expressed at a low constitutive level that was comparable to that of the endogenous $C D C 6$ in logarithmically growing cultures (data not shown). We then monitored the loss rate of a CEN plasmid from the mcm1-1 (pGAL:CDC6) cells and compared to that of the same strain carrying the vector alone (pGAL1). We observed a $34 \%$ loss rate per generation with the control cells and only a $3.5 \%$ loss rate for the mcm1-1 (pGAL-CDC6) cells. This 10-fold drop in the chromosome loss rate that results from ectopic expression of Cdc6 suggests that the role of $\mathrm{Mcm} 1$ in CDC6 transcription is the most probable cause of its minichromosome maintenance defect.

SWI4 and CLN3 are both rate limiting for the $G_{1}$ to $S$ transition

$\mathrm{Cln} 3$ and Swi4 play critical roles in activating the burst of CLN1 CLN2 transcription in late $\mathrm{G}_{1}$ (Nasmyth and Dirick 1991; Ogas et al. 1991; Dirick et al. 1995; Stuart and Wittenberg 1996), but the mechanism of that activation is not understood. We have shown that SWI4 and $C L N 3$ transcription is ECB regulated and peaks just before the peak of $C L N 1$ and $C L N 2$ transcription. Thus, it is possible that transcriptional control of SWI4 and $C L N 3$ allows these regulators to reach a level that promotes CLN1 and CLN2 transcription. If this is the case, expression of both proteins should be rate-limiting for $G_{1}$ progression, and even small changes in their rate of accumulation should effect the length of $G_{1}$. To test this prediction, we constructed diploid strains that were heterozygous for either SWI4 or $C L N 3$, or both. Figure 9A shows that SWI4 heterozygotes spend more time in $\mathrm{G}_{1}$ and that they are larger than wild-type diploid cells. This experiment shows that Swi4 is not in excess in wild-type cells and that a twofold change in SWI4 dosage is sufficient to prolong $G_{1}$. Many studies have shown that $C \ln 3$ is a dose-dependent activator of $\mathrm{G}_{1}$ progression /Cross 

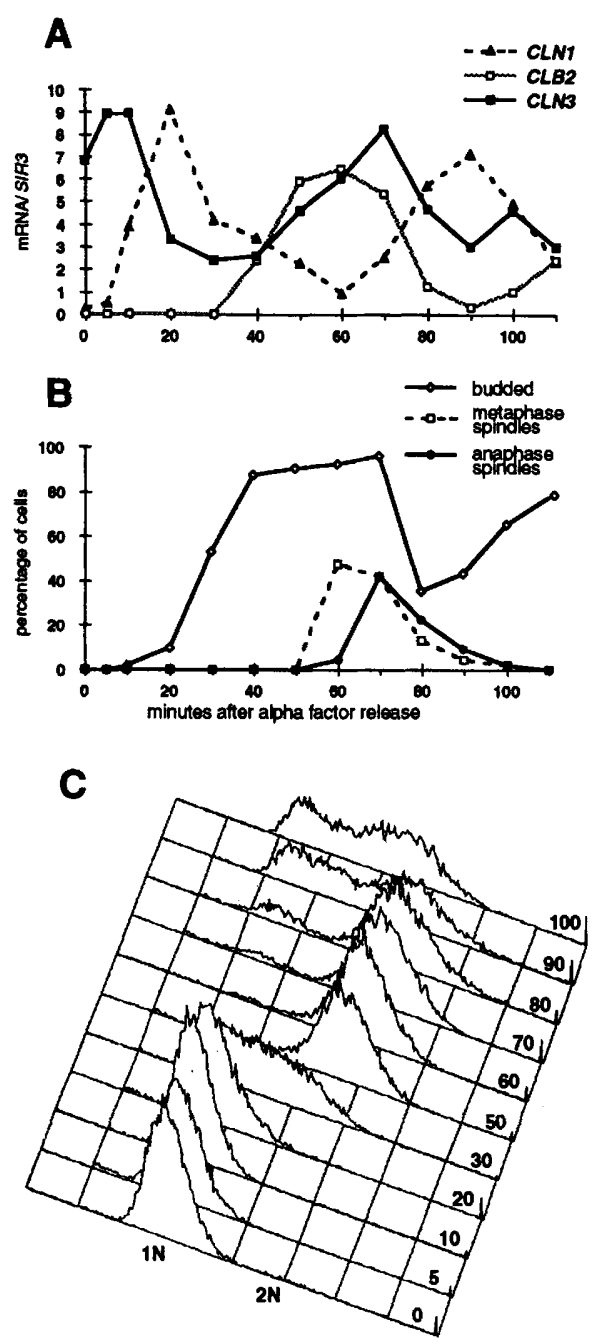

Figure 7. ECB-activated transcription peaks at the $M / G_{1}$ boundary of the cell cycle. An $\alpha$-factor arrest and release was performed and samples were taken at 10-min intervals for RNA isolation $(A)$, immunofluorescence $(B)$, and DNA content analysis $(C)$. (A) CLN3, CLN1, and CLB2 RNA levels were quantitated with respect to the SIR3 internal control as before. $(B)$ Budding, metaphase, and anaphase cells were scored from 150 to 200 cells. $(C)$ FACS analysis of DNA content through the cell cycle.

1988, 1989; Nash et al. 1988) and, as expected, we find that there is a clear size difference between diploids carrying zero, one, or two copies of CLN3 (Fig. 9B.) Moreover, size analyses of double heterozygotes show that the effects of reduced SWI4 and CLN3 gene dosage are additive. The cells maintain a successively larger size as the combined dose of these two genes is reduced. These data suggest that $\mathrm{Cln} 3$ and Swi4 provide independent, ratelimiting functions that promote the transition to $S$ phase, consistent with the suggestion that their transcriptional regulation is important for cell cycle controls.

\section{Discussion}

We have identified a cell cycle-regulated promoter ele- ment (ECB) that activates transcription at the $M / G_{1}$ boundary. The ECB was identified by dissection of the SWI4 promoter and then was found in the promoters of several other key regulators of the cell division cycle: $C D C 6, C D C 46, C D C 47$, and CLN3. The transcript levels of all of these genes peak at the $M / G_{1}$ boundary, and fragments of their promoters that contain the ECB elements confer early periodic transcription. The only sequence conserved among these promoter fragments is a 16-bp palindrome (TTt/aCCCnnnnAGGAAA), and two tandem copies of this sequence are sufficient to confer early cell cycle regulation to reporter constructs. Elimination of the ECB from the genomic SWI4 promoter causes a loss of the early wave of SWI4 transcription. Furthermore, mutation of the ECBs from the 600-bp $C L N 3$ promoter fragment disrupts the cell cycle regulation of that construct.

There is an Mcm 1-binding site at the center of the ECB element that is critical for its transcriptional activity. $\mathrm{Mcml}$ binds to these sites and is required for their activation. $\mathrm{Mcml}$ is a component of many transcription complexes and can act as an activator or a repressor, depending on the transcription factor with which it associates (Elble and Tye 1991). Most of the known Mcm1regulated promoters contain sites that are imperfect 16bp palindromes and do not bind $\mathrm{Mcml}$ or activate transcription on their own. Instead, associations between $\mathrm{Mcm} 1$ and other transcription factors that bind to adjacent sequences appear to be required to stabilize the complex and to confer specific regulatory properties (see Fig. 4). The ECB elements represent a new class of Mcm1-dependent promoter elements that activate transcription specifically at the $M / G_{1}$ boundary. They differ from the other Mcml-regulated elements in that they have a different, more extensive consensus sequence within the palindrome to which $\mathrm{Mcm} 1$ is known to bind (Herskowitz et al. 1992), and they do not contain or require adjacent binding sites for other transcription factors. Previous studies of the Mcml-binding sites in CLN3 indicate that the ECB elements are sites for $\mathrm{Mcml}$ binding in vitro and that $\mathrm{Mcml}$ alone can protect the entire ECB sequence (Kuo and Grayhack 1994). Thus, it is possible that $\mathrm{Mcml}$ is the only DNA-binding component required for ECB activation. If that is the case, its $M / G_{1}$ specificity may be conferred either by modifications of $\mathrm{Mcml}$ or by another protein that binds directly to $\mathrm{Mcml}$.

A systematic determination of the bases that are most critical for $M / G_{1}$-specific ECB activation will be required before we can identify all of the likely ECB-regulated genes. However, some of the $S$. cerevisiae genes required for mating contain $\mathrm{Mcm}$ l-binding sites that are quite similar to ECB elements, and two of these (STE2 and MFA2) are also cell cycle regulated (Oehlen et al. 1996). These promoters also contain consensus binding sites for Ste12, which cooperates with $\mathrm{Mcml}$ to increase basal transcription and to confer pheromone inducibility (Hwang-Shum et al. 1991; Errede and Ammerer 1989). However, the STE2 Mcml-binding site is capable of activating transcription on its own (Hwang-Shum et al. 
A

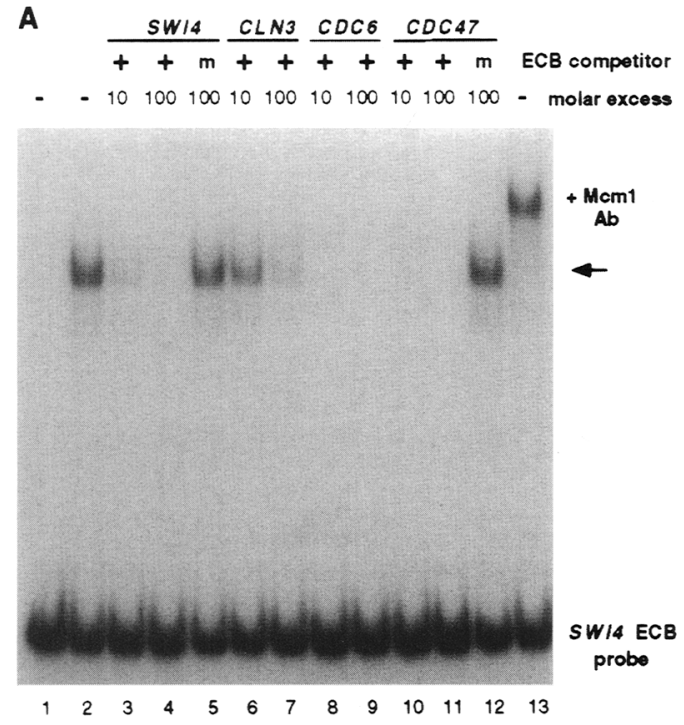

\section{B MCM1:VP16 CdC15}

$\begin{array}{llllllllllll}0 & 20 & 40 & 60 & 80 & 100 & 120 & 140 & 170 & 190 & 210 & 230\end{array}$
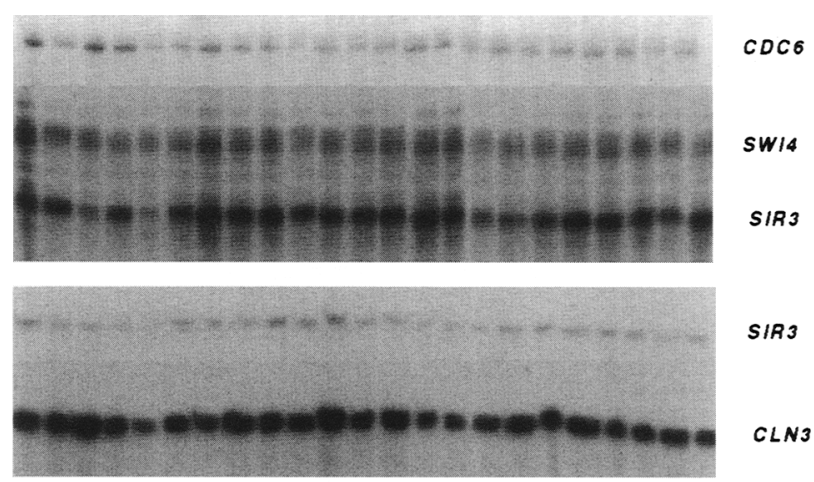

SIR3

CLN3

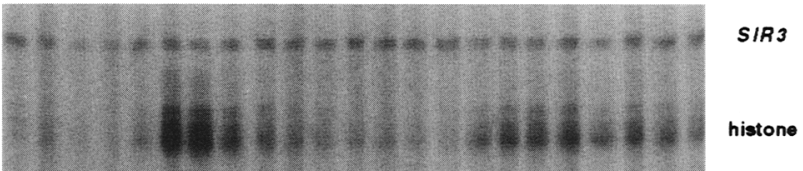

Figure 8. $\mathrm{Mcm} 1$ binds $\mathrm{ECBs}$ in vitro, and an $\mathrm{Mcm} 1-\mathrm{VP} 16$ fusion protein causes constitutive expression of ECB regulated genes in vivo. (A) Gel retardation assays using the $S W I 4 \mathrm{ECB}$ region as labeled probe (lane 2). Competition reactions with unlabeled wild-type $(+)$ ECB fragments from the SWI4 (lanes 3,4), CLN3 (lanes 6,7), CDC6 (lanes 8,9), and CDC47 (lanes 10,11) promoters added in 10 and $100 \mathrm{M}$ excess. Competitions were also carried out with swi4 and $c d c 47$ mutant (m) ECB fragments at $100 \mathrm{M}$ (lanes 5,12$)$. Lane 13 is identical to lane 2 except that $1 \mu \mathrm{l}$ of $\mathrm{Mcm} 1$ antibody was added. (B) BY2183 (MCM1-VP16 $c d c 15-1$ ) cells were released synchronously from a $c d c 15$ arrest and $C L N 3, C D C 6, S W I 4$, histone H2B (HTB1), and SIR3 mRNAs were monitored as in Figure 6. This experiment was also carried out with an isogenic MCM1 strain, and SWI4 transcript clearly oscillates in those cells (data not shown).

1991), so it is quite likely that the Mcm1-binding site in STE2 and perhaps others are of the ECB class, and that they also confer cell cycle regulation to these promoters. Mating only occurs during $\mathrm{G}_{1}$, so it may be optimal, or perhaps even essential in some instances, to express these mating-specific genes at the $M / G_{1}$ boundary.

$\mathrm{Mcm} 1$ is also required for transcription of the $\mathrm{G}_{2}$-specific transcripts (Lydall et al. 1991; Althoefer et al. 1995; Maher et al. 1995), which are transcribed immediately before the wave of ECB-activated transcription (see Fig. 6). The $\mathrm{G}_{2}$-specific promoter element includes an Mcm lbinding site and an adjacent site to which at least one other protein must bind (see Fig. 4). It will be interesting to determine how the rapid shift in the activity of $\mathrm{Mcml}$ from $\mathrm{G}_{2}$-specific promoters to ECBs takes place. In the case of one ECB-regulated gene, $C D C 6$, the $\mathrm{G}_{2}$-specific Swi5 protein is also required for maximum transcription (Piatti et al. 1995). Thus, it is possible that the CDC6 promoter is not accessible to $\mathrm{Mcm} 1$ until SWI5 is expressed in $G_{2}$. However, there are no Swi5-binding sites in the minimal ECB element, which is sufficient to confer $M / G_{1}$-specific transcription, so it is unlikely that Swi5 is a direct or essential regulator of ECB gene activation.

$\mathrm{Mcm} 1$ was originally identified as a gene required for efficient minichromosome maintenance, but it has since been demonstrated to be a transcription factor (Maine et al. 1984; Passmore et al. 1989; Ammerer 1990). None of its previously characterized target genes are involved in DNA replication. This has left the connection between
Mcml and DNA replication unexplained. However, three of the potential ECB-regulated genes: CDC6, $C D C 46$, and $C D C 47$ are required for DNA replication, and mutations in these genes result in the same minichromosome maintenance defects observed with $\mathrm{mcm} 1$ mutants (Maine et al. 1984; Palmer et al. 1990). Furthermore, we have found that low-level, Mcml-independent expression of CDC6 suppresses the minichromosome stability defect of $m \mathrm{~cm} 1-1$ cells. This strongly suggests that $\mathrm{Mcml}$ is not directly involved in DNA replication but, rather, that it is required, indirectly, for the transcription of $C D C 6$ and perhaps other DNA replication components.

$\mathrm{Mcml}$ also controls expression of two genes, SWI4 and $C L N 3$, which are known to be critical for entry into $\mathrm{S}$ phase and the transcription of the $\mathrm{G}_{1}$ cyclins CLN1 and CLN2 (Dirick et al. 1995; Stuart and Wittenberg 1996). Our studies with CLN3 and SWI4 heterozygotes indicate that these proteins are not in excess during the cell cycle. Rather, they provide independent, rate-limiting functions that affect the length of $G_{1}$. We speculate that the ECB-mediated transcription of these genes, peaking at the $M / G_{1}$ boundary, helps achieve the expression levels of these critical proteins that are required for activating CLN1 and CLN2 transcription and subsequent entry into $S$ phase. Consistent with this suggestion, we have shown that mutating the SWI4 ECB elements results in delayed SWI4 and CLN1 transcription and an extended $\mathrm{G}_{1}$. Efforts are under way to establish the significance of ECB regulation of $C L N 3$. In the case of $C L N 3$, the fluctuation 
A

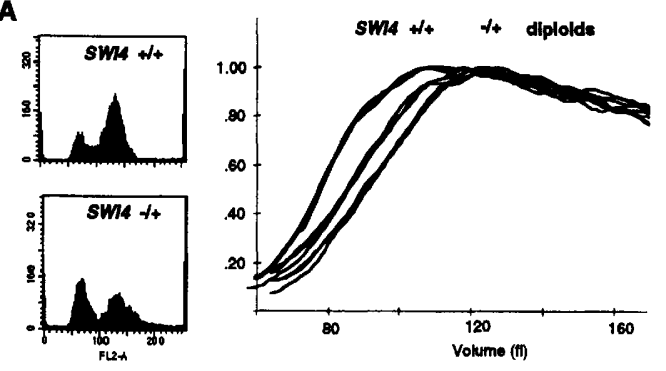

B
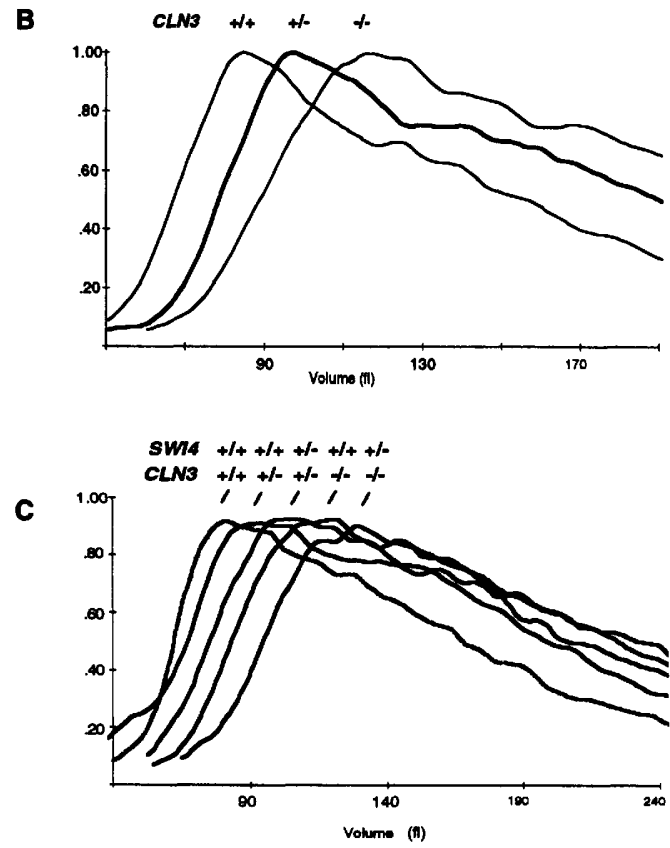

Figure 9. SWI4 and CLN3 are dose-dependent activators of $\mathrm{G}_{1}$ progression, and their effects are additive. These measurements were all carried out with exponential cultures grown in YEP glucose and isogenic strains. (A) FACS profiles of DNA content (left) and cell volume measurements (right) of $S W I 4 / S W I 4(+/+)$ and swi4/SWI4 $(-1+)$ diploids. swi4/swi4 cells could not be used in this analysis because SWI4 is essential in this strain background. (B) Cell volume measurements of wild-type $(+1+1$, CLN3 heterozygotes $(+1-)$ and $\operatorname{cln} 3$ deletion homozygotes $(-1-) .(C)$ Cell volume measurements of cells having one $(+\mid-)$ or two $(+1+)$ copies of SWI4 per diploid genome and zero $(-|-|$, one $1+1-1$, or two $1+1+1$ copies of CLN3.

in mRNA levels is much less than other ECB-regulated genes, or the other cyclins. However, numerous experiments have shown that cells are acutely sensitive to the gene dosage of this cyclin (Fig. 9; Cross 1988, 1989; Nash et al. 1988). Furthermore, it peaks at a time distinct from that of the other cyclins and consistent with its role to act with Swi4 to induce CLN1 and CLN2 transcription (Fig. 10).

As already discussed, the other group of genes that are controlled by $\mathrm{Mcm} 1$ and that are expressed at the $M / G_{1}$ boundary includes $C D C 6$ and $C D C 47$, which are required for the initiation of DNA synthesis. Thus, it appears that $\mathrm{Mcml}$ is controlling the expression of two groups of genes (see Fig. 10) that mediate progression into $\mathrm{S}$ phase, by activating $C L N 1$ and $C L N 2$ transcription and activating replication origins.

\section{Materials and methods}

Yeast strains and growth conditions

Wild-type cells (W303-1a) were used unless indicated otherwise (MATa leu2-3,112 trp1-1 his3-11,15 ade2-1 can1-100 ura3 ssd1d). Cells were grown in YEP or YC minimal medium supplemented as indicated (Sherman et al. 1994). $\alpha$-Factor and cdc15induced synchronies have been described (Sidorova et al. 1995). One-step gene replacements (Rothstein 1983) and lithium acetate transformation (Ito et al. 1983) were performed to introduce cln3::URA3 (Cross 1988) and/or swi4::HIS3 deletions into W303 homozygous diploids (BY609). The swi4::HIS3 deletion construct (pBD965) was made by replacing the Xhol-BamHI fragment of SWI4 with the HIS3 gene. Replacements were confirmed by Southern blots and PCR (Mullis and Faloona 1987), and site-directed mutants (Kunkel 1985) were all sequenced before and after insertion into the genome.

The chromosomal swi4ecb mutant was generated in BY1963, which is isogenic with W303-1a and carries a pGAL1:SWI4 plasmid (pBD896). First, the SWI4 promoter region was disrupted with URA3 using pBD1919 to produce BY2197. Then, ScaIcleaved pBD1920 (swi4ecb) DNA was used to replace the swi4::URA3 disruption to produce BY2197; then the pGAL1:SWI4 plasmid was lost from these cells to produce BY2196.

The MCM1-VP16 fusion (pBD1938) was integrated into an MCM1/mcm1::LEU2 heterozygous diploid (BY2010) at the

\section{M/ G1 G1/ S}

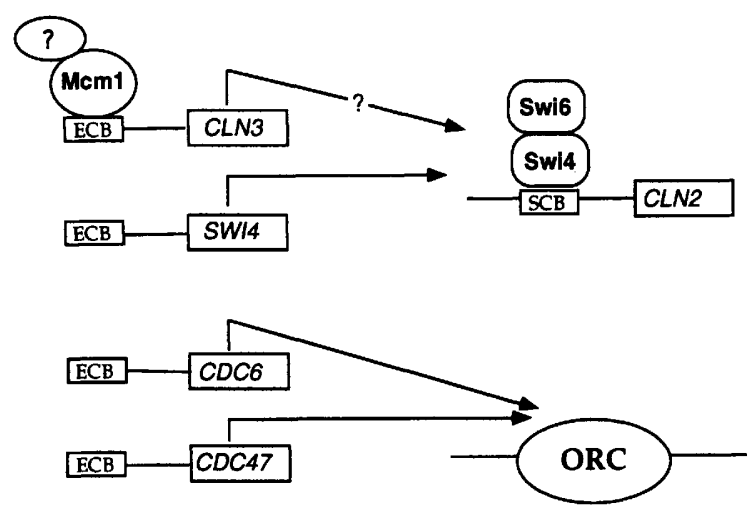

Figure 10. Two consecutive waves of transcription occur at the $M / G_{1}$ and $G_{1} / S$ transitions to produce critical regulators of the transition to S phase. SWI4, CLN3, CDC6, and CDC47 are transcribed at the $M / G_{1}$ boundary. Each of these genes contain $\mathrm{ECB}$ elements in their promoters, which bind the transcription factor $\mathrm{Mcml}$. Our data suggest that this wave of transcription prepares cells for the transition to $S$ phase in two ways. It induces the expression of several proteins that bind the origin recognition complex (ORC) and are required for the initiation of DNA replication. It also induces maximal transcription of two gene products (Cln3 and Swi4) that are rate limiting for the transition to $S$ phase and are known to activate $G_{1} / S$-specific transcription of $C L N 1$ and $C L N 2$ and many other genes. 
HIS3 locus. This strain was sporulated and $\mathrm{His}^{+} \mathrm{Leu}^{+}$spores were crossed with BY1782 (cdc15-1) to produce BY2183 (cdc15-1 mcm1-VP16::HIS3 mcm1::LEU2).

\section{Plasmid constructions}

pBD1478 contains promoter sequence from SWI4 $(-516$ to -395$)$ in $\mathrm{pBD} 1442$. pBD1442 is a UAS-deficient lacZ reporter construct derived from pSH144 (Foster et al.1993) in which a NotI sequence has been inserted downstream of the $X$ hoI cloning site for directional cloning. The SWI4 promoter sequences in pBD1478 (SWI4 $90 \mathrm{bp}$ ) were amplified from pBD1357 using oligonucleotides BD1371 (GCCAGCTCGAGTTGAAGTGACTCGTCAC) and BD1394 (GCCAGCTAGCGGCCGCCTTAGTCCTTGTTCCTC). pBD1357 was derived from pBD873 (Foster et al.1993). It contains a site-directed mutation of the most $3^{\prime} \mathrm{MCB}$ core sequence in the SWI4 promoter from CGCG to CTCT.

Mutation of the putative Mcml site within the SWI4 ECB region was performed by site-directed mutagenesis (Kunkel 1985 of pBD873 with the mutagenic oligonucleotide BL56 to generate $\mathrm{pBD} 1647$. This mutated $\mathrm{ECB}$ region was amplified by PCR using oligonucleotides BD1394 and BL23 (GCCAGCTCGAGCTCCCCGCCTGC), and subcloned into the XhoI-NotI sites of $\mathrm{pBD} 1442$ to generate $\mathrm{pBD} 1655$.

The ECB sites from the SWI4, CDC6, and CLN3 promoters were amplified and cloned into pBD1442. The CDC6 54-bp ECB sequence $(-199$ to -146$)$ was amplified from genomic library DNA with added XhoI and NotI sites and subcloned into pCR II (Invitrogen) and then into pBD1442 to generate the CDC6 ECB reporter construct pBD1637. The ECB region from SWI4 (-469 to -395 ) was amplified from pBD1478 and subcloned into $\mathrm{pBD} 1442$, as described above, to generate pBD1577. The CLN3 ECB sequences $(-994$ to -865$)$ were amplified from pC3C-1 (from J. Roberts, Fred Hutchinson Cancer Research Center), as described above, and cloned into pBD1442 to make pBD1791. Both strands of the CDC47 38-bp ECB DNA sequence (-232 to -195) were synthesized with XhoI and NotI cohesive ends and cloned directly into pBD1442 to produce pBD1951.

The ApaI-HindIII region encompassing the CLN3 promoter $(-1335$ to +711$)$ was subcloned from $\mathrm{pC} 3 \mathrm{C}-1$ into pBS KS- to generate $\mathrm{pBD} 1865$. The upstream Mcml sites in $\mathrm{pBD} 1865$ were mutated by site-directed mutagenesis to generate pBD1866. The mutagenic oligonucleotides changed nucleotides at $-954,-953$, and -952 from $C$ to $G$, nucleotides -894 and -893 from $G$ to $C$, and nucleotides -980 and -981 from $G$ to $C$. The CLN3 promoter driving $l a c Z$ transcription was generated by PCR amplification of CLN3 promoter sequence from pBD1865 (-994 to -439) with flanking $X h o I$ and NotI sites. This fragment was cloned into pBD1442, as described above, to generate pBD1790. The analogous plasmid, with all four potential Mcml-binding sites mutated (pBD1867), was generated in an analogous manner using the mutated $C L N 3$ promoter sequence in $\mathrm{pBD} 1866$, with a mutant $5^{\prime}$ primer to avoid regenerating the $\mathrm{Mcm} 1$-binding site during the PCR reaction.

The endogenous SWI4 promoter region was disrupted with pBD1919, which has SWI4 DNA from -508 to +334 replaced with the URA3 gene. Then, ScaI-cleaved pBD1920 (swi4ecb) DNA was used to replace the swi4::URA3 disruption. pBD1920 is pBSKS+ (Stratagene) containing SWI4 DNA from -1980 to +1912 in which the ECB element has been mutated to CCCGTTTACC by site-directed mutagenesis (Kunkel 1985).

CDC6 was amplified from -6 to +1681 from a MET:CDC6 plasmid (C2526) (Piatti et al. 1995) and cloned into pCR II (Invitrogen). This fragment was digested at the primer-derived
BamHI and KpnI sites and recloned into pYES2 (Invitrogen) to form $\mathrm{pGAL1:CDC6}$ (pBD1857).

The Mcml-VP16 construct fuses amino acids 1-154 of MCM1 to the 76 carboxy-terminal amino acids of VP16 (Triezeberg et al. 1988). To do this, a KpnI fragment of MCM1 from pSL1497 (Bruhn and Sprague 1994) was ligated to a KpnI PCR fragment containing VP16. A BamHI fragment containing this construct was ligated into the HIS3-integrating vector pRS303 (Sikorski and Hieter 1989) to make pBD1938.

\section{Transcript measurements}

S1 protection was used to measure transcript levels as described previously (Breeden and Mikesell 1991). To produce the CLN3 probe, a XhoI-HindIII fragment of CLN3 $(-412$ to +385$)$ was subcloned into $\mathrm{M} 13 \mathrm{mp} 18$, synthesis was primed within $1 a c Z$ $(+97$ to +80$)$ and released by cleavage with PfIM1. The SIR3 probe $(+1523$ to +1932$)$ in M13mpl9 was synthesized, as described above, and released by cleaving with HindIII. The CLB2 probe is an NheI-HinclI fragment inserted into $\mathrm{M} 13 \mathrm{mpl}$, primed for DNA synthesis with the M13 universal primer, and released by EcoRI cleavage. The CDC6 probe $(-299$ to +444$)$ is cloned into M13mp19 (BD1727), synthesized using the M13 universal primer, and liberated by cleavage with HindIII.

\section{PCR mutagenesis}

Mutagenesis of the SWI4 promoter was performed by mutagenic PCR as described (Cadwell and Joyce 1992), differing only in that $7 \mathrm{mM} \mathrm{MgCl}_{2}$ and an annealing temperature of $55^{\circ} \mathrm{C}$ were used. Products were cloned into pCR II, and recloned into pBD1442, as described above. Two independent pools of PCRmutated plasmids were generated (BD1498 and BD1656), transformed into wild-type cells, and assayed for $\beta$-galactosidase activity as colonies on filters (Breeden and Nasmyth 1985). Mutant plasmids were isolated, sequenced, and retransformed to confirm their phenotype. The autonomously replicating sequences were then eliminated from these plasmids by HindIII cleavage and religation; then they were integrated at the URA3 locus.

\section{Gel retardation assays}

Crude cell extracts from wild-type cells were generated and binding reactions carried out essentially as described (Lowndes et al. 1992; Sidorova and Breeden 1993). The SWI4 ECB probe was made using PCR and spanned the region from -468 to -395 . Competitor ECB DNAs were also made by PCR. These include the ECB regions from CLN3 (-996 to -864$), C D C 6(-200$ to -133 ), and $C D C 47$ (-232 to -195$)$. swi4ecb mutant competitor DNA spanned the same region and was amplified from BY2195. The $c d c 47 e c b$ mutant DNA was synthesized with substitution of TTT for AAA at positions starting at -195 and -211 . The antibody (from G. Sprague) used for supershifting was directed against Mcml amino acids 139-155 and has been characterized previously (Jarvis et al. 1989).

\section{Cell analysis and plasmid loss measurements}

Spindle microtubules and DNA were visualized as described previously (Kilmartin and Adams 1984; Sidorova et al. 1995). The DNA content of cells was measured by FACS analysis using a Becton Dickinson FACScan, with CellQuest and LYSYS II software. The distribution of cell sizes in exponentially growing populations of yeast was made using a Coulter Counter (Model ZM) with Sampling Stand (Model IIA) and Channelyzer 256. 
Samples were sonicated briefly and diluted $\sim 100$-fold in Isoton II (Coulter) before measurement. Cell volume data were accumulated until 500 cells with the modal cell volume had been measured. The data were exported from the Channelyzer to an Excel version 5.0 spreadsheet, and the point values for each distribution were smoothed by nine iterations of the following algorithm $\left(x_{n-1}+2 x_{n}+x_{n+1}\right) / 4$ and plotted.

Plasmid loss rate was measured as in Chen and Tye (1995), with BY2076, which is a ura3 derivative of SY1672 (a leu2-3,112 his $4 \Delta 34 \mathrm{mcm} 1-1)$ made by fluoro-orotic acid selection (Boeke et al.1984). This strain, carrying the pRS315 (CEN) plasmid (Sikorski and Hieter 1989), as well as either pGAL:CDC6 or the parent vector (pYES2, Invitrogen), was grown in raffinose minimal media for $\sim 10$ generations under conditions that selected only for the pGAL-based vectors. Then the cells were plated with or without selection for pRS315 to determine the final stability $(F)$ or the fraction of cells that had lost the plasmid. Two independent experiments were carried out with essentially the same result. These data were averaged and expressed as percent plasmid loss per generation $(R)$, where $R=F^{1 / N}$ after $N$ generations of nonselective growth.

\section{Acknowledgments}

We gratefully acknowledge G. Sprague and J. Kilmartin for generously providing the $\mathrm{Mcml}$ and tubulin antibodies, respectively; N. Steele for her help with the initial CDC6 experiments; P. Rabinovitch for advice about analyzing Coulter Counter data; and J. Roberts, J. Cooper, and members of the laboratory for helpful comments about the manuscript. We also thank J. Sidorova and K. Heichman for help with the immunofluorescence and FACS; M. Roth for the use of his microscope, M.A. Osley for providing a CLB2 plasmid; T. Knight for image analysis; and P. Huff for manuscript preparation. J.F.P. was supported by a Human Frontiers in Science Fellowship. This research was funded by a grant (GM41073) from the National Institutes of Health to L.L.B.

The publication costs of this article were defrayed in part by payment of page charges. This article must therefore be hereby marked "advertisement" in accordance with 18 USC section 1734 solely to indicate this fact.

\section{References}

Althoefer, H., A. Schleiffer, K. Wassmann, A. Nordheim, and G. Ammerer. 1995. Mcml is required to coordinate G2-specific transcription in Saccharomyces cerevisiae. Mol. Cell. Biol. 15: 5917-5928.

Ammerer, G. 1990. Identification, purification, and cloning of a polypeptide (PRTF/GRM) that binds to mating-specific promoter elements in yeast. Genes \& Dev. 4: 299-312.

Baroni, M.D., P. Monti, and L. Alberghina. 1994. Repression of growth-regulated $G_{1}$ cyclin expression by cyclic AMP in budding yeast. Nature 371: 339-342.

Barral, Y., S. Jentsch, and C. Mann. 1995. $\mathrm{G}_{1}$ cyclin turnover and nutrient uptake are controlled by a common pathway in yeast. Genes \& Dev. 9: 399-409.

Boeke, J., F. Lacroute, and G. Fink. 1984. A positive selection for mutants lacking orotidine- 5 ' phosphate decarboxylase activity in yeast: 5-Fluoro-orotic acid resistance. Mol. \& Gen. Genet. 197: 345-346.

Breeden, L. 1996. Start-specific transcription in yeast. Curr. Top. Microb. Immunol. 208: 95-127.

Breeden, L. and G. Mikesell. 1991. Cell cycle-specific expression of the SWI4 transcription factor is required for the cell cycle regulation of $H O$ transcription. Genes \& Dev. 5: 1183-1190. 1994. Three independent forms of regulation affect expression of $H O, C L N 1$ and $C L N 2$ during the cell cycle of Saccharomyces cerevisiae. Genetics 138: 1015-1024.

Breeden, L. and K. Nasmyth. 1985. Regulation of the yeast $H O$ gene. Cold Spring Harbor Symp. Quant. Biol. 50: 643-650.

Brewer, B.J. and W.L. Fangman. 1987. The localization of replication origins on ARS plasmids in S. cerevisiae. Cell 51: 463 471.

Bruhn, L. and G.F. Sprague, Jr. 1994. MCM1 point mutants deficient in expression of a-specific genes: Residues important for interaciton with a1. Mol. Cell. Biol. 14: 2534-2544.

Bueno, A. and P. Russell. 1992. Dual functions of CDC6: A yeast protein required for DNA replication also inhibits nuclear division. EMBO I. 11: 2167-2176.

Cadwell, R.C. and G.F. Joyce. 1992. Randomization of genes by PCR mutagenesis. PCR Methods Applic. 2: 28-33.

Chen, Y. and B.-K. Tye. 1995. The yeast $\mathrm{Mcm} 1$ protein is regulated posttranscriptionally by the flux of glycolysis. Mol. Cell. Biol. 15: 4631-4639.

Cross, F.R. 1988. DAF1, a mutant gene affecting size control, pheromone arrest, and cell cycle kinetics of Saccharomyces cerevisiae. Mol. Cell. Biol. 8: 4675-4684.

. 1989. Further characterization of a size control gene in Saccharomyces cerevisiae. J. Cell Sci. (Suppl.) 12: 117-127.

- 1995. Starting the cell cycle: What's the point? Curr. Opin. Cell Biol. 7: 790-797.

Dalton, S. and L. Whitbread. 1995. Cell cycle-regulated nuclear import and export of $\mathrm{Cdc} 47$, a protein essential for initiation of DNA replication in budding yeast. Proc. Natl. Acad. Sci. 92: 2514-2518.

Dirick, L., T. Bohm, and K. Nasmyth. 1995. Roles and regulation of Cln-Cdc28 kinases at the start of the cell cycle of Saccharomyces cerevisiae. EMBO T. 14: 4803-4813.

Elble, R. and B.K. Tye. 1991. Both activation and repression of a-mating type-specific genes in yeast require transcription factor Mcm1. Proc. Nat1. Acad. Sci. 88: 10966-10970.

Errede, B. and G. Ammerer. 1989. STE12, a protein involved in cell-type-specific transcription and signal transduction in yeast, is part of protein-DNA complexes. Genes \& Dev. 3: $1349-1361$.

Fernandez-Sarabia, M.J., A. Sutton, T. Zhong, and K.T. Arndt. 1992. SIT4 protein phosphatase is required for the normal accumulation of SWI4, CLN1, CLN2, and HCS26 RNAs during late $G_{1}$. Genes \& Dev. 6: 2417-2428.

Foster, R., G.E. Mikesell, and L. Breeden. 1993. Multiple Swi6dependent cis-acting elements control SWI4 transcription through the cell cycle. Mol. Cell. Biol. 13: 3792-3801.

Gordon, C.B. and J.L. Campbell. 1991. A cell cycle-responsive transcriptional control element and a negative control element in the gene encoding DNA polymerase $\alpha$ in Saccharomyces cerevisiae. Proc. Natl. Acad. Sci. 88: 60586062.

Herskowitz, I., J. Rine, and J. Strathern. 1992. Mating-type determination and mating-type interconversion in Saccaromyces cerevisiae. In The molecular and cellular biology of the yeast Saccharomyces cerevisiae (ed. E.W. Jones, J.R. Pringle, and J.R. Broach|, pp. 583-656. Cold Spring Harbor Laboratory Press, Cold Spring Harbor, N.Y.

Hogan, E. and D. Koshland. 1992. Addition of extra origins of replication to a minichromosome suppresses its mitotic loss in cdc6 and cdc14 mutants of Saccharomyces cerevisiae. Proc. Natl. Acad. Sci. 89: 3098-3102.

Hwang-Shum, J.-J., D.C. Hagen, E.E. Jarvis, C.A. Westby, and G.F. Sprague, Jr. 1991. Relative contributions of MCM1 and STE12 to transcriptional activation of a- and $\alpha$-specific genes 
from Saccharomyces cerevisiae. Mol. \& Gen. Genet. 227: 197-204.

Ito, H., Y. Fukada, K. Murata, and A. Kimura. 1983. Transformation of intact yeast cells treated with alkali cations. $J$. Bacteriol. 153: 163-168.

Jarvis, E.E., K.L. Clark, and G.F. Sprague. 1989. The yeast transcription activator PRTF, a homolog of the mammalian serum response factor, is encoded by the MCM1 gene. Genes \& Dev. 3: 936-945.

Johnson, A.D. 1995. Molecular mechanisms of cell-type determination in budding yeast. Curr. Opin. Genet. \& Dev. 5: 552-558.

Kelly, T.J., G.S. Martin, S.L. Forsburg, R.J. Stephen, A. Russo, and P. Nurse. 1993. The fission yeast $c d c 18^{+}$gene product couples S phase to START and mitosis. Cell 74: 371-382.

Kilmartin, J.V. and A.E.M. Adams. 1984. Structural rearrangements of tubulin and actin during the cell cycle of the yeast Saccharomyces. I. Cell Biol. 98: 922-933.

Kunkel, T.A. 1985. Rapid and efficient site-specific mutagenesis without phenotypic selection. Proc. Natl. Acad. Sci. 82: 488-492.

Kuo, M.H. and E. Grayhack. 1994. A library of yeast genomic MCM1 binding sites contains genes involved in cell cycle control, cell wall and membrane structure, and metabolism. Mol. Cell. Biol. 14: 348-359.

Lew, D.J. and S.I. Reed. 1993. Morphogenesis in the yeast cell cycle: regulation by $\mathrm{Cdc} 28$ and cyclins. I. Cell Biol. 120: 1305-1320.

Lowndes, N.F., C.J. McInerny, A.L. Johnson, P.A. Fantes, and L.H. Johnston. 1992. Control of DNA synthesis genes in fission yeast by the cell-cycle gene $c d c 10^{+}$. Nature 355: 449453.

Lydall, D., G. Ammerer, and K. Nasmyth. 1991. A new role for MCM1 in yeast: Cell cycle regulation of SWI5 transcription. Genes \& Dev. 5: 2405-2419.

Maher, M., F. Cong, D. Kindelberger, K. Nasmyth, and S. Dalton. 1995. Cell cycle-regulated transcription of the CLB2 gene is dependent on $\mathrm{Mcm} 1$ and a ternary complex factor. Mol. Cell. Biol. 15: 3129-3137.

Maine, G.T., P. Sinha, and B.-K. Tye. 1984. Mutants of S. cerevisiae defective in the maintenance of minichromosomes. Genetics 106: 365-385.

McIntosh, E.M., T. Atkinson, R.K. Storms, and M. Smith. 1991. Characterization of a short, cis-acting DNA sequence which conveys cell cycle stage-dependent transcription in Saccharomyces cerevisiae. Mol. Cell. Biol. 11: 329-337.

Mullis, K. and F. Faloona. 1987. Specific synthesis of DNA in vitro via a polymerase-catalyzed chain reaction. Methods Enzymol. 155: 335-350.

Nash, R., G. Tokiwa, S. Anand, K. Erickson, and A.B. Futcher. 1988. The WHII gene of Saccharomyces cerevisiae tethers cell division to cell size and is a cyclin homolog. EMBO $T$. 7: 4335-4346.

Nasmyth, K. and L. Dirick. 1991. The role of SWI4 and SWI6 in the activity of G1 cyclins in yeast. Cell 66: 995-1013.

Oehlen, L.J.W.M. and F.R. Cross. 1994. $\mathrm{G}_{1}$ cyclins CLN1 and $C L N 2$ repress the mating factor response pathway at Start in the yeast cell cycle. Genes \& Dev. 8: 1058-1070.

Oehlen, L.J.W.M., J.D. McKinney, and F.R. Cross. 1996. Ste12 and $\mathrm{Mcml}$ regulate cell cycle-dependent transcription of FAR1. Mol. Cell. Biol. 16: 2830-2837.

Ogas, J., B.J. Andrews, and I. Herskowitz. 1991. Transcriptional activation of $C L N 1, C L N 2$, and a putative new G1 cyclin (HCS26) by SWI4, a positive regulator of G1-specific transcription. Cell 66: 1015-1026.

Palmer, R.E., E. Hogan, and D. Koshland. 1990. Mitotic trans- mission of artificial chromosomes in cdc mutants of the yeast, Saccharomyces cerevisiae. Genetics 125: 763-774.

Passmore, S., R. Elble, and B.-K. Tye. 1989. A protein involved in minichromosome maintenance in yeast binds a transcriptional enhancer conserved in eukaryotes. Genes \& Dev. 3: 921-935.

Piatti, S., C. Lengauer, and K. Nasmyth. 1995. Cdc6 is an unstable protein whose de novo synthesis in $\mathrm{G}_{1}$ is important for the onset of $S$ phase and for preventing a "reductional" anaphase in the budding yeast Saccharomyces cerevisiae. EMBO I. 14: 3788-3799.

Rothstein, R. 1983. One step gene disruption in yeast. Methods Enzymol. 101: 202-211.

Sherman, F., G.R. Fink, and J.B. Hicks. 1994. Methods in yeast genetics, Cold Spring Harbor Laboratory, Cold Spring Harbor, New York.

Sidorova, J. and L. Breeden. 1993. Analysis of the SWI4/SWI6 protein complex, which directs $G_{1} / S$-specific transcription in Saccharomyces cerevisiae. Mol. Cell. Biol. 13: 1069-1077.

Sidorova, J., G. Mikesell, and L. Breeden. 1995. Cell cycle regulated phosphorylation of Swi6 controls its nuclear localization. Mol. Biol. Cell 6: 1641-1658.

Sikorski, R.S. and P. Hieter. 1989. A system of shuttle vectors and yeast host strains designed for efficient manipulation of DNA in Saccharomyces cerevisiae. Genetics 122: 19-27.

Sprague, G.F., Jr. and J.W. Thorner 1992. Pheromone response and signal transduction during the mating process of Saccharomyces cerevisiae. In The molecular and cellular biology of the yeast Saccharomyces cerevisiae led. E.W. Jones, J.R. Pringle, and J.R. Broach), pp. 657-744. Cold Spring Harbor Laboratory Press, Cold Spring Harbor, NY.

Stillman, B. 1996. Cell cycle control of DNA replication. Science 274: 1659-1664.

Stuart, D. and C. Wittenberg. 1996. CLN3, not positive feedback, determines the timing of CLN2 transcription in cycling cells. Genes \& Dev. 9: 2780-2794.

Tokiwa, G., M. Tyers, T. Volpe, and B. Futcher. 1994. Inhibition of Gl cyclin activity by the Ras/cAMP pathway in yeast. Nature 371: 342-345.

Triezeberg, S.T., R.C. Kingsburg, and S.L. McKnight. 1988. Functional dissection of VP16, trans-activator of herpes simplex virus immediate gene expression. Genes \& Dev. 2: 718729.

Tyers, M., G. Tokiwa, and B. Futcher. 1993. Comparison of the Saccharomyces cerevisiae $\mathrm{G}_{1}$ cyclins: $\mathrm{Cln} 3$ may be an upstream activator of $C \ln 1, C \ln 2$ and other cyclins. EMBO $\%$. 12: 1955-1968.

Wittenberg, C., K. Sugimoto, and S.I. Reed. 1990. Gl-specific cyclins of $S$. cerevisiae: Cell cycle periodicity, regulation by mating pheromone, and association with the p34CDC28 protein kinase. Cell 62: 225-237.

Wynne, J. and R. Treisman. 1992. SRF and MCM1 have related but distinct DNA binding specificities. Nucleic Acids Res. 20: 3297-3303.

Zwerschke, W., H.-W. Rottjakob, and H. Kuntzel. 1994. The Saccharomyces cerevisiae CDC6 gene is transcribed at late mitosis and encodes a ATP/GTPase controlling S phase initiation. J. Biol. Chem. 269: 23351-23356. 


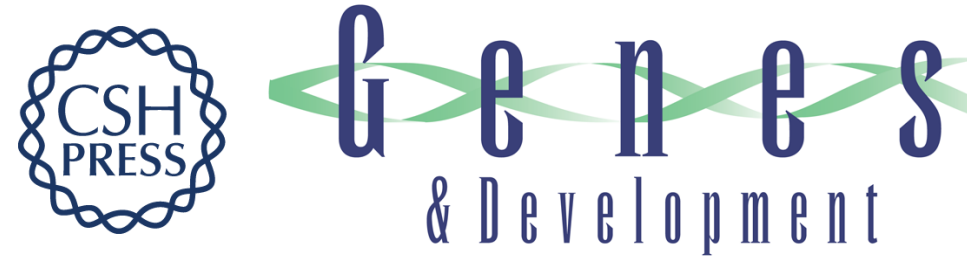

\section{A novel Mcm1-dependent element in the SWI4, CLN3, CDC6, and CDC47 promoters activates M/G1-specific transcription.}

C J Mclnerny, J F Partridge, G E Mikesell, et al.

Genes Dev. 1997, 11:

Access the most recent version at doi:10.1101/gad.11.10.1277

References This article cites 60 articles, 36 of which can be accessed free at:

http://genesdev.cshlp.org/content/11/10/1277.full.html\#ref-list-1

License

Email Alerting

Service

Receive free email alerts when new articles cite this article - sign up in the box at the top right corner of the article or click here.

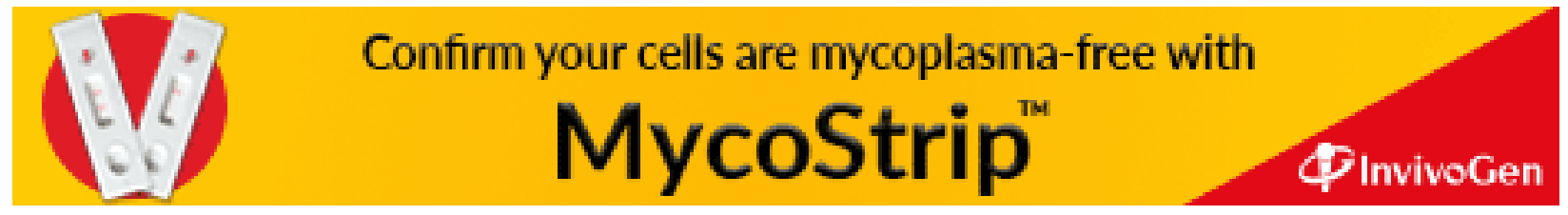

